\title{
Experiências Lógico-matemáticas: Objeto de Aprendizagem de Uso Integrado de Recursos Manipulativos Digitais
}

\author{
Alexandre Ramos de Araujo \\ Faculdade Adventista Paranaense (FAP) \\ Ivatuba - PR - Brasil \\ alexandreraraujo@gmail.com
}

\begin{abstract}
This article presents learning objects developed with Adobe Flash, integrated with a MySql database, which allows a greater interaction between students and teachers. The implementation of this proposal, anchored in the Piagetian theory of knowledge construction, resulted in a set of data that allows us to analyze the possibilities of building an environment that provides logical-mathematical experiences. It presents also, analysis of situations in which the objects were used. Perspectives of continuation and expansion of developing materials are placed as closure of the text.
\end{abstract}

Resumo. Este artigo apresenta objetos de aprendizagem desenvolvidos com Adobe Flash, integrados a um banco de dados MySql, que permite uma interação maior entre alunos e professores. A implementação dessa proposta, ancorada na teoria piagetiana de construção de conhecimentos, resultou num conjunto de dados que nos permite analisar as possibilidades de construção de um ambiente que proporcione experiências lógico-matemáticas. Apresenta, também, análise de situações em que os objetos foram utilizados em um curso de formação continuada para professoras de Educação Infantil. Perspectivas de continuação e expansão da elaboração de materiais são apontadas como fechamento do texto.

\section{Introdução}

As situações que vivenciamos são, em geral, fontes para a construção do nosso conhecimento. Na exploração e na interação com as diversas possibilidades descobremse as qualidades e limites dos sistemas conceituais. Sistemas que, em muitos momentos, não são suficientes para resolver determinadas situações, necessitando a intermediação de um agente que faça intervenções, proponha questionamentos, apresente sugestões de procedimentos que criem situações de desequilíbrio cognitivo.

Os objetos de aprendizagem que não apresentam desafios podem limitar todo o processo de construção do conhecimento a sensações e à percepção. Proporcionar uma interação baseada na percepção pode não ser o suficiente para promover a reflexão e a análise. Quanto mais interação um objeto proporcionar, melhor será o aprendizado. Mais que motivador, um objeto de aprendizagem deve servir como um meio de provocar desequilíbrio cognitivo do sujeito. Ou seja, a prática construtivista baseada na teoria de Piaget requer o desenvolvimento de objetos com os quais os sujeitos possam interagir, explorar suas características em busca da construção de conhecimento. A interação sujeito-objeto pode promover esta construção de conhecimento, porém de 
forma limitada, uma vez que os conceitos do sujeito estão em constante (re)construção. Para aumentar as possibilidades se faz necessário a mediação. A mediação consiste em levantar questionamentos que propiciem ao sujeito visualizar novas relações no objeto.

Este artigo apresenta uma reflexão sobre objetos de aprendizagem, estes baseados na teoria construtivista de Jean Piaget, desenvolvidos para apoiar a construção do conceito de classificação. Tais objetos apresentam a possibilidade de trocas entre alunos e professores. Inicialmente, na seção 2, apresentamos a fundamentação teórica, ancorada em Jean Piaget sobre experiências lógico-matemáticas e a importância das mesmas na construção do conhecimento. Na seção 3, apresentam-se os objetos de aprendizagem desenvolvidos para auxiliar na construção do conceito de classificação. A quarta seção apresenta as considerações finais, e por fim, são expostas as referências bibliográficas utilizadas.

\section{Fundamentação Teórica}

De acordo com o construtivismo piagetiano, o desenvolvimento do conhecimento distingue-se em três tipos: o físico, o lógico-matemático e o social.

O conhecimento social são as convenções construídas pela sociedade, na cultura em que o sujeito está inserido. Por exemplo, as palavras um, dois, três, quatro são exemplos de conhecimento social, pois cada cultura tem um conjunto de palavras diferentes utilizadas para representar os números. O próprio sistema de numeração que se utiliza hoje é um conhecimento social. Apesar de haver regras que organizam a contagem, com a intenção de facilitar a memorização da ordem dos algarismos, existem variações de um sistema de numeração para outro.

Já o conhecimento físico apoia-se sobre as características materiais do objeto, aquilo que pode ser observado, como cor, textura e forma, por exemplo. São propriedades intrínsecas ao objeto e são reconhecidas pela percepção. Vamos tomar como exemplo uma bola. A sua cor vermelha, a sua forma esférica, o material com que foi construída são conhecimentos físicos que podemos obter com base na observação e experimentação. Piaget (1995) designou esta atividade mental como capaz de abstrair as propriedades dos objetos por abstração empírica.

Segundo Piaget (1978), o conhecimento lógico-matemático é construído a partir de uma ação mental sobre o objeto. Tal conhecimento não é inerente ao objeto, e sim, construído a partir de relações que o sujeito elabora no seu pensamento. Diferente do conhecimento físico, que consiste basicamente na abstração do conteúdo do objeto, o conhecimento lógico-matemático é construído a partir das coordenações de ações sobre o objeto. Comparar duas pessoas e dizer que a pessoa A é menor que a pessoa B é um exemplo de conhecimento lógico-matemático. A característica de menor ou maior não existe na pessoa A nem na pessoa $\mathrm{B}$ em si, mas existe na mente do indivíduo que realiza a comparação. Dessa forma, Piaget (1995) designa esse tipo de abstração, característica da experiência lógico-matemática, por abstração reflexionante.

É importante salientar que o conhecimento físico depende do conhecimento lógico-matemático e vice-versa. Tome-se, por exemplo, uma bola. Para "ler" a forma esférica da bola, é necessário que o sujeito tenha construído uma estrutura que permita classificar as formas, distinguindo a forma esférica de todas as demais. E ele só 
VI Congresso Brasileiro de Informática na Educação (CBIE 2017)

Anais do XXVIII Simpósio Brasileiro de Informática na Educação (SBIE 2017)

consegue realizar esta diferenciação da forma porque observa as propriedades do objeto. Kamii (1995, p.18) diz:

“[...] um sistema de referência lógico-matemático (construído pela abstração reflexiva) é necessário para a abstração empírica, porque nenhum fato poderia ser "lido" a partir da realidade externa se cada fato fosse um pedaço isolado do conhecimento já construído numa forma organizada".

Portanto, experiências baseadas na repetição e percepção não são suficientes para que o sujeito aprenda um determinado conceito, é necessário possibilitar situações nas quais ele tenha a oportunidade de coordenar ações, fazer escolhas, comparações, por exemplo.

Existe, portanto, uma diferença entre as experiências que priorizam o conhecimento social e as que priorizam o conhecimento lógico-matemático: de um lado, uma seleção de experiências baseadas na reprodução e, de outro lado, uma generalização com compreensão progressiva de todas as possibilidades inerentes apresentadas ao sujeito e, em seguida, uma reflexão sobre esta ação, que se constitui em interpretar para construir novos conhecimentos.

Piaget (1978, p. 176) afirma, ainda, que “[...] compreender é conseguir dominar, em pensamento, as mesmas situações até poder resolver os problemas por ela levantados, em relação ao porquê e ao como das ligações constatadas e, por outro lado, utilizadas na ação"[sic]. Com base nessas ideias, pode-se dizer que o sujeito se constrói à medida que entende as diferentes relações entre os objetos do mundo que o cerca.

Se oportunizada ao sujeito a reflexão sobre os resultados obtidos e desafiados com situações inéditas, obter-se-á uma chance maior de que esse sujeito esteja atento aos conceitos envolvidos na situação experimentada. Essas questões são importantes não só para compreender a forma por meio da qual professor e alunos devem se relacionar, mas também para caracterizar a qualidade das interações que os alunos deverão ter a partir das atividades propostas. Não deve ser um simples fazer, um chegar a uma resposta certa, mas um trabalho com intenção, para proporcionar um ambiente propício às transformações dos esquemas. Esse trabalho deve apresentar atividades ricas em aberturas para novos desafios para o aluno e para o professor.

\section{Objetos Virtuais}

Nas próximas linhas serão apresentados dois objetos desenvolvidos com a intenção de auxiliar na construção do conceito de classificação.

Classificar consiste em reunir objetos que apresentam uma determinada característica em comum, separando-os dos que dele diferem nessa mesma característica. Essa operação lógico-matemática é importante ao desenvolvimento humano, pois ajuda a organizar a vida. Há uma constante classificação na vida humana: um bebê classifica se um objeto é sugável ou não (neste caso, ainda não existe uma classificação operatória); classificam-se as compras do supermercado quando essas são colocadas em ordem dentro do armário, as roupas dentro das gavetas ou ainda quando se organiza uma estante de livros. Mas a classificação não é realizada somente de forma concreta, visto que, quando é dito que há um gosto pelas azaleias, faz-se um 
VI Congresso Brasileiro de Informática na Educação (CBIE 2017)

Anais do XXVIII Simpósio Brasileiro de Informática na Educação (SBIE 2017)

agrupamento de flores que apresentam certas qualidades, separando-as de outras que não as têm.

Os objetos de aprendizagem foram desenvolvidos com o software Adobe Flash ${ }^{1}$, uma ferramenta de criação de animações para a web que permite ao programador o desenvolvimento de aplicações que possibilitam ao usuário manipular o objeto, arrastando e soltando elementos, escrevendo textos, apresentando também outras funcionalidades.

Uma das possibilidades apresentadas nestes objetos é que as ações do usuário ficam registradas em um banco de dados MySql. Isso foi possível através de uma integração entre o Flash, ActionScript e PHP.

A Actionscript é uma linguagem de programação orientada a objetos criada para desenvolvimento de jogos e animações. Suas facilidades e potencialidades transformamna numa excelente opção para desenvolvimento de objetos de aprendizagem. Já o PHP é uma linguagem de script utilizada em ambientes web que pode ser embutida dentro do HTML.

O objetivo destes objetos é proporcionar a vivência de atividades de sala de aula, de forma virtual e interativa.

\subsection{Objeto 1}

No primeiro objeto, o usuário é representado pela imagem de uma boneca e precisa classificá-la em diversas situações.

$\mathrm{Na}$ tela de apresentação, o usuário deve escrever login e senha para entrar nas salas, onde cada usuário será representado por um desenho.

Em cada uma das salas, o usuário deve escolher qual critério sua representação satisfaz. Para mover a sua representação, basta clicar nela e arrastá-la com o botão esquerdo do mouse pressionado. Ao chegar ao local desejado, basta soltar o botão do mouse. Caso a ilustração não satisfaça nenhuma das opções, deve deixá-la no espaço em branco.

\footnotetext{
${ }^{1}$ Em 2016, o Adobe Flash foi substituído pelo Adobe Animate CC. Esta substituição se fez necessária para que a ferramenta acompanhass as tecnologias HTML5 Canvas e WebGL nativo.
} 


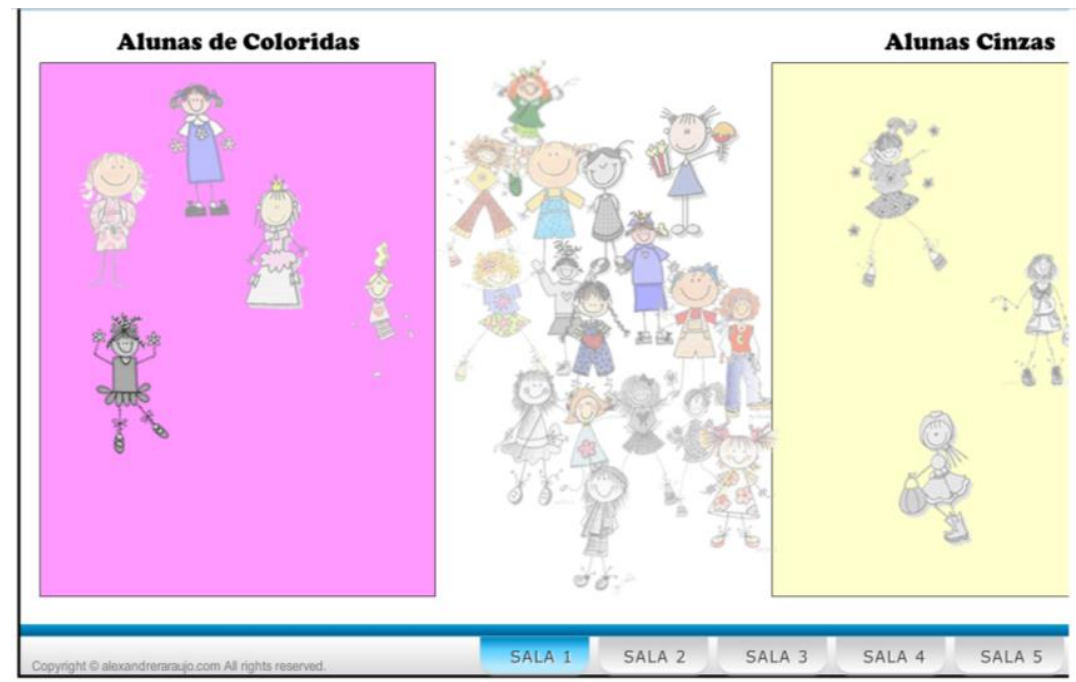

Figura 1. Objeto 1 - Espaço onde o usuário deve realizar as classificações

A Figura 1 é um exemplo de uma das situações na qual o usuário deve escolher qual sentença satisfaz as características da sua "aluna". Ao todo são seis situações:

- Alunas coloridas / Alunas cinza;

- Alunas de cabelos soltos / alunas de cabelo presos;

- Alunas de vestidos ou saias / Alunas de calças ou bermudas;

- Alunas com cabelos presos e roupas azuis / Alunas com cabelos soltos;

- Alunas com roupas não azul / Alunas com cabelos sem enfeite;

- Alunas com roupas sem coração ou sem flores / Alunas com roupas azuis ou com flores.

Para acessar as diferentes salas, o usuário deve utilizar o menu no fundo da tela, que estará visível após o login. Em cada uma das salas encontrará uma das situações, apresentadas acima, na qual deverá classificar a sua boneca.

O usuário pode transitar de forma livre entre as salas e, a cada vez que soltar a boneca, as coordenadas de posição ficam gravadas no banco de dados, possibilitando ao professor verificar qual sentença foi escolhida pelo aluno.

\subsection{Objeto 2}

O segundo objeto tem como objetivo a classificação de pares de calçados. Na primeira tela, o usuário deve escrever login e senha para entrar nas salas, onde encontrará as situações que deve resolver.

Em cada uma das salas são apresentadas sentenças que expõem os critérios de classificação dos calçados. Para mover os desenhos, basta clicar neles e arrastá-los com o botão esquerdo do mouse pressionado. Ao chegar ao local desejado, basta soltar o botão do mouse. Caso a ilustração não satisfaça nenhuma das opções, o desenho deve ficar no espaço em branco. 
VI Congresso Brasileiro de Informática na Educação (CBIE 2017)

Anais do XXVIII Simpósio Brasileiro de Informática na Educação (SBIE 2017)

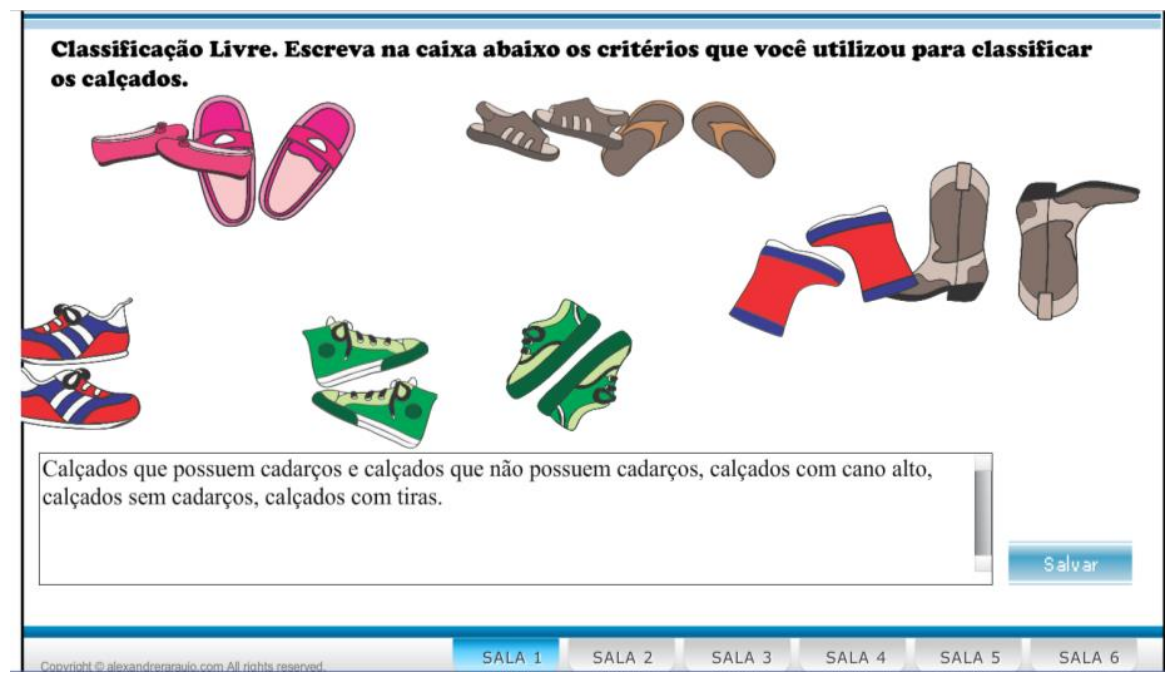

Figura 2. Objeto 2 - Espaço onde o usuário deve realizar as classificações

A Figura 2 é um exemplo de uma das situações em que o usuário deve realizar a classificação dos calçados. Ao todo são seis situações:

- Classificação Livre. Escreva na caixa abaixo os critérios que você utilizou para classificar os calçados;

- Calçados marrons / Calçados rosa;

- Calçados vermelhos com cadarços / Calçados marrons com velcros;

- Calçados não marrons e não cadarço / Calçados não verdes e não saltos;

- Escreva os critérios utilizados para classificar os calçados;

A quinta e a sexta situações são idênticas. São apresentados os calçados classificados por determinada característica, e o usuário deve analisar a situação e escrever, em uma caixa de texto, qual é a característica utilizada para classificar os calçados.

Para navegar entre as salas, o usuário deve utilizar o menu no fundo da tela, que estará visível após o login. Em cada uma das salas encontrará uma das situações que cujo critério de classificação deverá analisar. Neste objeto, diferentemente do primeiro, o usuário deve clicar no botão salvar para gravar, no banco de dados, as coordenadas das imagens e textos.

\section{Experimentos e Análise de Resultados}

Para mensurar a eficiência dos objetos de aprendizagem, direcionaram-se os trabalhos para a aplicabilidade da mesma dentro do ambiente escolar. Esses objetos foram utilizados em um curso de formação continuada a distância, de professores de Educação Infantil, com oito participantes.

No primeiro objeto, classificação das bonecas, todos os cursistas realizaram as atividades de forma correta e sem apresentar problemas. Já no segundo objeto, alguns participantes não conseguiram realizar todas as atividades de forma correta, por tal motivo vamos analisar o segundo objeto. 
VI Congresso Brasileiro de Informática na Educação (CBIE 2017)

Anais do XXVIII Simpósio Brasileiro de Informática na Educação (SBIE 2017)

Na Sala1 é solicitado que o usuário realize uma classificação livre, ou seja, ele deve criar os critérios de classificação. Apenas um usuário não conseguiu realizar a atividade corretamente. $\mathrm{Na}$ figura 3 é possível verificar que este usuário não compreendeu que ele deveria classificar os calçados, escrevendo como critério de classificação "sapatos de todos os tipos".

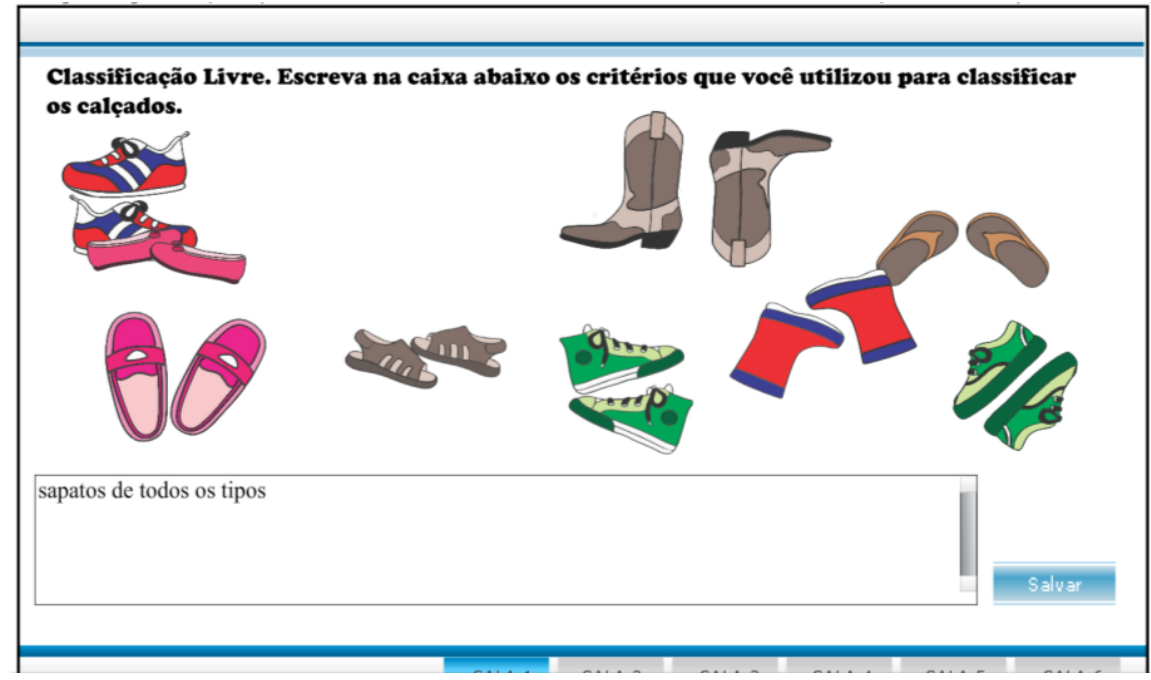

Figura 3. Tela da Sala 1 de um usuário

Outro exemplo que apresentamos é o da Sala 5, Figura 4, em que são apresentados ao aluno os calçados já classificados e é solicitado que o mesmo escreva na caixa de texto qual foi o critério utilizado para realizar a classificação.

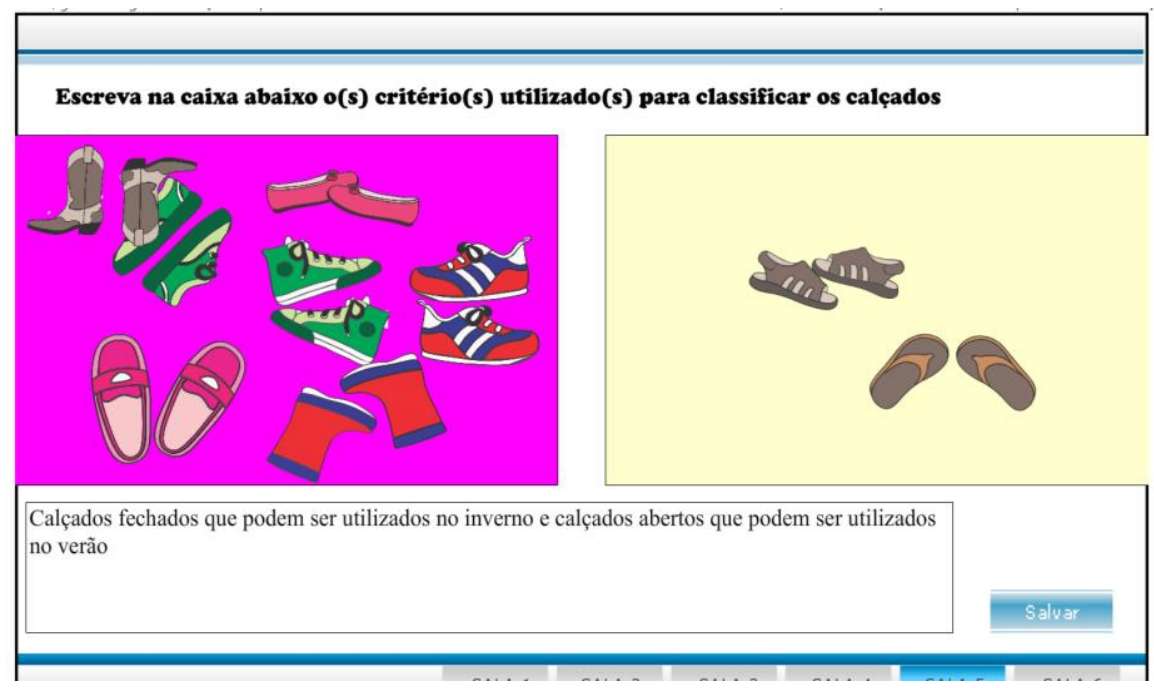

Figura 4. Tela da Sala 3 de um usuário

A partir da resposta apresentada na Figura 4 é possível conversar com o aluno sobre os diversos conceitos que estão implícitos na resposta. Por exemplo: Não usamos chinelos no inverno? Não usamos sapatilhas no verão?

O critério apresentado pelo aluno não está claro e, por isso, deve ser reformulado. Essa constatação só é possível pelo fato de que as respostas do usuário ficam gravadas em um banco de dados. A análise destas respostas e a troca com o aluno 
VI Congresso Brasileiro de Informática na Educação (CBIE 2017)

Anais do XXVIII Simpósio Brasileiro de Informática na Educação (SBIE 2017)

possibilitam que exista uma reflexão sobre a resposta, o que pode levar a um desequilíbrio cognitivo, e a busca pelo reequilíbrio proporciona a (re)construção de conceitos.

Outras respostas apresentadas foram: "Coloridos, com salto, cadarço e sem cadarço marrom e cinza sem salto"; "sandálias e sapatos"; "calçados fechados e calçados abertos", "foram classificados pelas cores".

Destaca-se que cada aluno criou um critério diferente para uma mesma situação, o que possibilita uma riqueza de discussão sobre os distintos conceitos que os alunos têm sobre o mesmo assunto. Estas trocas só foram possíveis pelo fato de que as respostas apresentadas pelos alunos ficaram gravadas, possibilitando ao professor analisar e compreender os conceitos dos alunos. O papel do professor, neste caso, vai além do de alguém que apresenta um objeto de aprendizagem, mas é o de quem proporciona ao aluno um momento de reflexão, análise e reconstrução.

\section{Conclusões}

Esse artigo apresentou dois objetos de aprendizagem desenvolvidos para auxiliar na construção do conceito de classificação. Os objetos foram aplicados em um curso de formação continuada a distância de professores de Educação Infantil, possibilitando realizar, de forma virtual, atividades que colocamos em prática em cursos presenciais. Neste curso foi possível verificar a eficiência do objeto de aprendizagem em poder discutir as respostas dos alunos e auxiliá-los na reconstrução de conceitos.

Em cada um dos objetos, os cursistas foram agentes ativos na construção do conhecimento, desenvolvendo experiências lógico-matemáticas, e não apenas reprodutivas ou perceptivas. Em cada atividade, dos objetos, foi possível comparar, criar hipóteses e analisar situações, e tudo isso ficou registrado em bancos de dados, a fim de que o professor pudesse examinar minuciosamente e transformar em subsídios para trocas com os alunos.

O trabalho prossegue com a intenção de melhorar a interação entre aluno e professor. Entre as possibilidades de melhoria, destacamos a inserção de um espaço de comentários para o professor, em que ele pode deixar registradas suas observações sobre a resposta do aluno. Outra sugestão é a possibilidade de visualizar as respostas dos colegas e poder discuti-las, confrontando seus critérios de classificação. Consideramos que as trocas entre os usuários são importantes, uma vez que concordamos com Nevado (2014), sobre sua ideia de que uma abordagem para objetos de aprendizagem não deva se limitar à discussão do objeto em si, mas sim de todo o processo desenvolvido por professores e alunos.

\section{Referências}

Kamii, C. (1996) A criança e o número: implicações educacionais da teoria de Piaget para a atuação junto a escolares de 4 a 6 anos. Papirus Editora.

Nevado, R.A.(2014) Ambientes virtuais de aprendizagem: do ensino na rede à aprendizagem em rede. In: Salto para o Futuro - Boletins 2005. Disponível em: $<$ http://www.tvebrasil.com.br/salto/boletins2005/nfa/tetxt2.htm $>$. Acesso em: 14 jul. 2017. 
VI Congresso Brasileiro de Informática na Educação (CBIE 2017)

Anais do XXVIII Simpósio Brasileiro de Informática na Educação (SBIE 2017)

Piaget, J. (1978) Fazer e Compreender. São Paulo, Melhoramentos, Editora da Universidade de São Paulo.

Piaget, J. et al.(1995) Abstração reflexionante: relações lógico-aritméticas e ordem das relações espaciais. Porto Alegre, ArtMed. 